\title{
Parental bonding styles in schizophrenia, depressive and bipolar patients: a comparative study
}

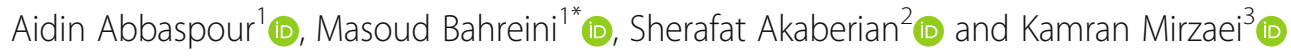

\begin{abstract}
Background: Numerous bio-psychosocial factors play a role in the etiology of psychiatric disorders. In this regard, the relationship between parents and their children is significantly involved in developing the offspring mental health. However, there is no clear-cut answer as to which parental bonding style is more strongly associated with psychiatric diseases of patients. This study aimed to compare parental bonding styles in patients with schizophrenia, depression, and bipolar disorder in Bushehr province, Iran in 2018.

Methods: In this cross-sectional comparative study, 130 patients with schizophrenia, depression, and bipolar disorder who referred to four outpatients psychiatric centers in Bushehr were selected using quota sampling. The patients were assessed and compared in terms of parental bonding styles. Data were collected using a valid and reliable parental bonding instrument (PBI). Data were analyzed using SPSS software (ver. 22), Chi-square and KruskalWallis tests at a significant level of 0.05 .

Results: Results showed that the optimal parental bonding style (low control, high care) in bipolar disorder (43.05\%), major depression (47.7\%), and schizophrenia (38.5\%) was the most prevalent style of parental bonding; however, $62.30 \%$ of the above patients suffered from inefficient paternal bonding styles and $51.53 \%$ from inefficient maternal bonding styles. Furthermore, the patients' maternal bonding styles were significantly different $(p=0.007)$ while their paternal bonding styles did not show any significant differences $(p=0.848)$.

Conclusions: Most of the patients with psychiatric disorders were affected by ineffective parenting styles. The results also confirmed that despite the several bio-psycho-social factors involved in the development of psychiatric disorders, the crucial roles of parents, especially mothers, should not be ignored. It was further suggested that parents and parental bonding were important and fundamental factors for mental health promotion.
\end{abstract}

Keywords: Bipolar disorder, Depression, Parental bonding, Schizophrenia

\footnotetext{
* Correspondence: m.bahreini@bpums.ac.ir

${ }^{1}$ Nursing and Midwifery School, Bushehr University of Medical Sciences, Bushehr, Iran

Full list of author information is available at the end of the article
}

(C) The Author(s). 2021 Open Access This article is licensed under a Creative Commons Attribution 4.0 International License, which permits use, sharing, adaptation, distribution and reproduction in any medium or format, as long as you give appropriate credit to the original author(s) and the source, provide a link to the Creative Commons licence, and indicate if changes were made. The images or other third party material in this article are included in the article's Creative Commons licence, unless indicated otherwise in a credit line to the material. If material is not included in the article's Creative Commons licence and your intended use is not permitted by statutory regulation or exceeds the permitted use, you will need to obtain permission directly from the copyright holder. To view a copy of this licence, visit http://creativecommons.org/licenses/by/4.0/ The Creative Commons Public Domain Dedication waiver (http://creativecommons.org/publicdomain/zero/1.0/) applies to the data made available in this article, unless otherwise stated in a credit line to the data. 


\section{Background}

Psychiatric disorders are increasing and significantly affecting the public health all over the world [1]. These disorders usually occur with psychological and behavioral manifestations which lead to significant functional deficiencies. Among the psychiatric disorders, schizophrenia, bipolar disorder, and depression are particularly important with the highest bed occupancy rates in psychiatric wards. Schizophrenia is a severe psychiatric disorder involving delusions and hallucinations. Depression is characterized by feeling sad, anhedonia, guilt, and suicidal thoughts, and bipolar is defined as periods of depression, elevated mood, over activity, reduced need for sleep, and pressured speech [2]. There are 20 million people with schizophrenia, about 45 million cases of bipolar disorder, and 264 million people with major depression around the world [3]. In Iran, demographic studies have reported the prevalence of these three disorders to be 25 to $31 \%$ [4].

Such diseases entail serious ramifications for patients and affect their interpersonal relationships and personal and social performance. Feelings of helplessness, hopelessness, worthlessness, stigma, fear, vulnerability, and low quality of life are among such consequences [3]. Various biological, familial, psychosocial, and spiritual factors are involved in the etiology of these disorders. These factors can be considered as predisposing, precipitating, and perpetuating factors [5]. Family, as one the most important factors, could impact the mental health of the members [6]. In Iran, the recent socio-economic changes, advances in technology, fading family traditions, more women's social activities, and employment of both parents outside home have led to the investigation of the role of family, especially parents, in the development of children's mental health.

Over the past decade, some studies have reported that the quality of life is lower in patients with mental disorders than the general public [7]. These investigations have raised questions led to further research on relationships among family members and its effects on children's mental health. Accordingly, the available scientific evidence has hypothesized that family or parents can have critical parts in the occurrence of certain mental disorders. Bowlby's concepts of attachment have been applied to psychopathology and to the psychological understanding of psychiatry disorders. Bowlby related deficient/pathological parenting with lack of care and excessive control/protection dimensions [8]. On this account, family relationships, particularly parents' roles in the family and children's mental development, can be considered and studied as strong variables influencing the children's future mental health [9]. In this regard, the concept of parental bonding has been specifically taken into consideration by researchers worldwide [10]. According to Bowlby's theory of attachment, parents who are unable to either establish warm, loving, and close relationships with their children or provide the necessary environment for their children's independent development, raise their children in an atmosphere of anxiety, leading to psychological disorders [11]. The concept of parental bonding also focuses on the quality of the relationship between parents and offspring throughout their life. A warm relationship with adequate parental care and control (optimum parental bonding) plays an important role in the development children's mental health. On the contrary, dysfunctional parenting leads to problems in interpersonal relationships and psychiatric disorders caused by the cold relationship between parents and children, inadequate care, and excessive control or rejection of children [12]. As a leading researcher in this field, Parker has introduced the dual styles of parental bonding in a continuum. The first style, "caring parental bonding", reflects a warm, close, and empathetic relationship as opposed to a cold, rejecting, and neglecting relationship. The second style is the "over protection" or "control parental bonding" which involves parents' severe control and protection over their children, leading to the non-completion of independence in the children [13].

Studies focusing on the concept of parental bonding have examined the association between parental bonding in childhood and psychiatric symptoms in adulthood $[14,15]$. For instance, a study in Brazil compared the parental bonding styles of parents of schizophrenic and bipolar patients. Based on their results, there were significant differences between parental bonding styles in these two diseases, especially among the maternal bonding styles [16]. In a review article, researchers discussed research concerning the association between parental bonding in childhood and psychiatric symptoms in adulthood. They found that neglectful relationships (low care) and overprotection seem to represent risk factors for the development of psychiatric symptoms in offspring [17]. Another study was conducted to determine the relationship between parental bonding and attitudes toward suicide in medical students in Japan. The researchers concluded that high levels of maternal care ensured reduced suicidal ideation [18]. In Iran, results of a cross-sectional study on university students showed that the students who experienced a less caring parental bonding style, had significantly higher psychological symptoms, particularly depression, anxiety, and paranoia [19]. In this study, researchers investigated the healthy dormitory students of a university in Iran. On the contrary, the results of another study in Iran revealed that depression and lack of self-confidence rates in children 
significantly increased in parenting styles in which parents exaggerated in caring for or controlling their children [20].

Health care providers should target both patients and their families, necessitating an accurate evaluation of family performance [21]. A review of the related literature also indicates that relatively few studies have addressed psychiatric patients, and most have mainly focused on samples other than psychiatric patients. This research gap is more evident in Iran. Due to the increasing prevalence of psychiatric disorders and the undeniable role of family in the development of children's mental health, there is an urgent need for more detailed studies in this field.

\section{Aim and hypotheses}

This study aimed to evaluate and compare parental bonding styles in patients with schizophrenia, depression, and bipolar disorders in Bushehr, Iran. Based on the aforementioned studies [16 and 17] and the attachment theory, we have hypothesized that: (1) maternal and paternal care score in patients with schizophrenia would be higher than patients with BD and MDD (mood disorders), (2) maternal and paternal control score in patients with schizophrenia would be lower than patients with BD and MDD and (3) non optimal parental bonding styles would be more common in patients with schizophrenia than patients with BD and MDD.

\section{Methods}

\section{Design and participants}

In this cross-sectional comparative study, conducted in the adult psychiatric clinics in Bushehr, southwestern Iran, the study population consisted of Patients with confirmed diagnosis of schizophrenia, BD and MDD. Diagnostic interviews include psychiatric interview and mental status examination performed by a psychiatrist during outpatient visits as a part of a routine care. The inclusion criteria for patients were as follows: (a) diagnosis of schizophrenia, BD, or MDD in accordance with the criteria of the DSM-5, (b) age $\geq 18$ years, (c) patients who were not in the acute phase of the disease, (d) Patients who have lived with their parents for the first 16 years of their life (e) patients whose both of their parents have no history of serious mental illnesses, and (f) patients without any known systemic or neurological diseases that may confound cognitive performance. Illiterate patients, psychiatric hospitalization within the past 6 months, patients with intellectual disabilities (diagnosed by DSM-5) and those who refused to give informed consent or to answer the questionnaire were excluded from the study.

We used the quota sampling method for each disease. Based on the score of parental bonding tool in patients with schizophrenia and bipolar disorder in a study by Gomez et al. [16], using the sample size formula $(\mathrm{N}=$ $\mathrm{z} 1-\alpha / 22 \mathrm{~S} 2 / \mathrm{d} 2$ (and assuming that $\alpha=0.05$ and $\mathrm{d}=0.3 \mathrm{~S}$, we specified the sample size of different disorders as follows; at least 43 patients with schizophrenia and a minimum of 43 patients with bipolar. According to the parental bonding scores of depressed patients in a study by Bahreini et al. [19], the sample size for patients with depression was estimated to be at least 44 . In performing the pairwise comparison between the parental bonding styles of patients with schizophrenia, bipolar disorder, and depression, the sample size obtained through sample size formula for pairwise comparison, $(N=2(\mathrm{z} 1-\alpha / 2+\mathrm{z} 1-\beta) 2$ $\left.\mathrm{S} 2 / \mathrm{d} 2, \mathrm{~S}^{2}=\left(\mathrm{s}_{1}{ }^{2}+\mathrm{s}_{2}{ }^{2}\right) / 2, \mathrm{~d}^{2}=\left(\mu_{1}-\mu_{2}\right)^{2}\right)$, was less than that calculated for each group when $\alpha=0.05$ and study power $=80 \%$; therefore, the minimum sample size was assumed to be equal to the minimum sample size of each group.

\section{Data collection}

Data were collected from September 2018 to December 2018. To this end, we visited three public psychiatric clinics and a private psychiatric center in Bushehr and explained the research purpose to patients after making sure of the inclusion criteria. Afterwards, the questionnaires were given to eligible patients who had provided the written informed consent. Each patient was asked to complete the questionnaires within almost 10 to $12 \mathrm{~min}$. The measure was completed for both mothers and fathers separately.

For data collection, we used Parker's parental bonding instrument (PBI). This 25-item instrument is applicable to adolescents who are 16 years or older [22]. The measure is 'retrospective', meaning that adults (over 16 years) complete the measure for how they remember their parents during their first 16 years. Of the 25 items, 12 belong to "care" (score range: 0 to 36 ) and 13 belong to "control" (overprotection) (score range: 0 to 39). Thirteen items were directly scored while 12 items were inversely scored. Direct scoring was conducted in a way that "very like" received a score of 3, "moderately like" received score 2, "moderately unlike" received score 1 , and "very unlike" received score 0 . In this questionnaire, care items 1, 5, 6, 11, 12, 17 and control items 8, 9, 10, $13,19,20$, and 23 were directly scored. Care items 2,4 , $14,16,18,24$ and control items $3,5,7,15,21,22$, and 25 were indirectly scored. For mothers, the cut-off scores were 27 and 13.5 for care and control, respectively; for fathers, these scores were 24 and 12.5. In addition to generating care and protection scores for each scale, parents were effectively assigned based on the individual's responses to one of four quadrants: optimal parenting (low control, high care), affectionless control (low care, high control), affectionate constraint (high 
care, high control), and neglectful parenting (low care, low control) [13]. The instrument's validity has been confirmed in various studies and its content validity index was 0.81 . Also, its reliability was reported to be suitable for mothers and fathers with Cronbach's alpha coefficient of 0.79 to 0.88 [23].

\section{Ethical considerations}

This study was approved by the Ethics Committee of the Deputy of Research and Information Technology at Bushehr University of Medical Sciences (IR.BPUMS.REC.1396.40). All procedures performed in study involving human participants were in accordance with the ethical standards of the institutional and/or national research committee and with the 1964 Helsinki declaration and its later amendments or comparable ethical standards. All participants and parents/legal guardians gave their written informed consent after having been enlightened the details of the procedure. Confidentiality of information and anonymity were among the other issues that were emphasized.

\section{Data analysis}

The data were analyzed using SPSS 22 (SPSS, Chicago, IL, USA). Mean, standard deviation, percentages, and frequency were used for data description. Normality of variables was checked using the Shapiro-Wilk test, which showed that they did not follow normal distribution. For inferential analysis, we employed the Chi-square and Kruskal-Wallis tests at a significant level of 0.05 .

\section{Results}

We assessed 147 patients based on inclusion and exclusion criteria out of which 130 subjects were eligible and therefore provided consent. All the participants answered all the questions and none chose to withdraw from the study. This study included 44 depressed patients with a mean age of $31.09 \pm 7.7$ years, 43 schizophrenic patients with a mean age of $31.56 \pm 5.77$ years, and $43 \mathrm{bi}$ polar patients with a mean age of $30.51 \pm 7.74$ years. Most participants were male $(n=73,56.15 \%)$, single $(n=76,58.46 \%)$ and had a high school education $(n=$ $57,43.84 \%)$ and a history of hospitalization $(n=72$, $55.38 \%$ ) (Table 1).

Based on the findings, the hypothesis 1 was not supported. Accordingly, in all three groups, mean of paternal and maternal care was less than the cut-off point (low care), but there was no significant difference among the patients. However, the means of paternal and maternal control of patients were significantly different $(p=$ 0.001 and $p=0.024$, respectively); as a result, the control scores of both parents of bipolar patients were higher than the depressed and schizophrenic patients (Table 2). These finding supported hypothesis 2 . Moreover, in general, 81 patients (62.30\%) experienced non optimal

Table 1 Demographic characteristics of participants

\begin{tabular}{|c|c|c|c|c|c|}
\hline \multicolumn{2}{|c|}{ Demographic characteristics } & \multirow{2}{*}{$\begin{array}{l}\text { depression } \\
21(47.7)\end{array}$} & \multirow{2}{*}{$\frac{\text { bipolar }}{20(46.5)}$} & \multirow{2}{*}{$\begin{array}{l}\text { schizophrenia } \\
16(37.2)\end{array}$} & \multirow{2}{*}{$\frac{\boldsymbol{p} \text {-value }}{0.559}$} \\
\hline gender & female & & & & \\
\hline & male & $23(52.3)$ & $23(53.5)$ & $27(62.8)$ & \\
\hline \multirow[t]{3}{*}{ Marital status } & married & $13(29.5)$ & $15(34.9)$ & $9(20.9)$ & 0.082 \\
\hline & divorce & $1(2.3)$ & $7(16.3)$ & $9(20.9)$ & \\
\hline & single & $30(68.2)$ & $21(48.8)$ & $25(58.2)$ & \\
\hline \multirow[t]{4}{*}{ Patient Education status } & Elementary school & $0(0)$ & $0(0)$ & $2(4.7)$ & 0.001 \\
\hline & Under diploma & $8(18.2)$ & $14(32.5)$ & $27(62.7)$ & \\
\hline & diploma & $21(47.7)$ & $22(51.2)$ & $14(32.6)$ & \\
\hline & academic & $15(34.1)$ & $7(16.3)$ & $0(0)$ & \\
\hline \multirow[t]{2}{*}{ Father education status } & literate & $41(93.2)$ & $39(90.7)$ & $35(81.4)$ & 0.068 \\
\hline & illiterate & $2(6.8)$ & $4(9.3)$ & $8(18.6)$ & \\
\hline \multirow[t]{2}{*}{ Mother education status } & literate & $38(86.4)$ & $32(74.4)$ & $26(60.5)$ & 0.023 \\
\hline & illiterate & $6(13.6)$ & $11(25.6)$ & $17(39.5)$ & \\
\hline \multirow[t]{2}{*}{ Father job } & employed & $40(90.9)$ & $38(88.4)$ & $40(93)$ & 0.757 \\
\hline & unemployed & $4(9.1)$ & $5(11.6)$ & $3(7)$ & \\
\hline \multirow[t]{2}{*}{ Mother job } & employed & $12(27.3)$ & $15(34.9)$ & $8(18.6)$ & 0.235 \\
\hline & unemployed & $32(72.7)$ & $28(65.1)$ & $35(81.4)$ & \\
\hline \multirow[t]{2}{*}{ History of admission } & yes & $8(18.2)$ & $25(58.1)$ & $39(90.7)$ & 0.001 \\
\hline & no & 36 (81.8) & $18(41.9)$ & $4(9.3)$ & \\
\hline
\end{tabular}


Table 2 Mean and standard deviation of fundamental parental bonding styles in psychiatric patients

\begin{tabular}{llllll}
\hline Fundamental parental bonding styles & Depression $(\mathbf{M} \pm \mathbf{S D})$ & Bipolar $(\mathbf{M} \pm \mathbf{S D})$ & Schizophrenia $(\mathbf{M} \pm \mathbf{S D})$ & $\boldsymbol{p}$-value \\
\hline Mother & care & $23.95 \pm 5.72$ & $23.28 \pm 6.47$ & $25.23 \pm 6.90$ & 0.219 \\
& control & $16.18 \pm 5.67$ & $19.95 \pm 7.97$ & $14.14 \pm 6.51$ & 0.001 \\
Father & care & $23.68 \pm 5.02$ & $22.60 \pm 7.30$ & $24.58 \pm 6.41$ & 0.447 \\
& control & $16.77 \pm 5.99$ & $19.28 \pm 8.75$ & $14.74 \pm 6.81$ & 0.024 \\
\hline
\end{tabular}

paternal styles, and 67 patients (51.54\%) experienced non optimal maternal styles. "Neglectful parenting" was also recognized in both fathers and mothers as the most inefficient parenting style (Fig. 1).

The comparison of paternal bonding styles among schizophrenic, depressed, and bipolar patients revealed that the most frequent paternal bonding styles were "optimal parenting" followed by "neglectful parenting" with a slight difference among the three groups. The paternal bonding styles did not show any significant difference between the fathers of the three groups $(p=0.848)$ (Table 3). Meanwhile, mothers of patients with schizophrenia (60.5\%) used non optimal parental styles more than mothers of depressed and bipolar patients. These results revealed a significant difference between the patients' maternal bonding styles $(p=0.007)$ (Table 3$)$ and supported hypothesis 3 . Statistical analysis indicated no association between the demographics' of participants and their parental bonding styles.

\section{Discussion}

The present study aimed to determine and compare parental bonding styles in the parents of patients with schizophrenia and mood disorders including depression and bipolar disorders. The results showed that the mean parental care was not significantly different among the patients; on the other hand, their mean parental control was significantly different, and the paternal and maternal control scores were higher in bipolar patients compared with schizophrenic patients. In other words, parents of bipolar patients are more protective and controlling. This result is consistent with the studies in European and Latin American countries despite the difference in the cultural and social characteristics $[12,16]$. In another study carried out in Japan, subjects who experienced "paternal affectionless control" displayed less ability to adapt with anxiety and stress, leading to mental disorders in these individuals [24]. The attachment theory of Bowlby underscores that inefficient parental style such as excessive control can make children more prone to mental disorders [11].

In addition, the results of the present study indicated no significant differences among patients with schizophrenia, depression, and bipolar disorder in terms of paternal bonding styles. However, most of the patients described their paternal styles as inefficient. Among the inefficient styles, the most prevalent one was "neglectful parenting", observed in almost one third of the three groups. In this style of parenting, characterized by low protection and care, the father does not have enough control over the children's behavior, nor does he provide enough care. There is compelling scientific evidence which introduces childhood neglect as a risk factor for mental disorders in adulthood [25]. In a study in Italy, a strong relationship was observed between parents' emotional neglect and children's mental disorders [26]. Emotional neglect usually stems from a parent's failure or refusal to satisfy their children's psychological needs.

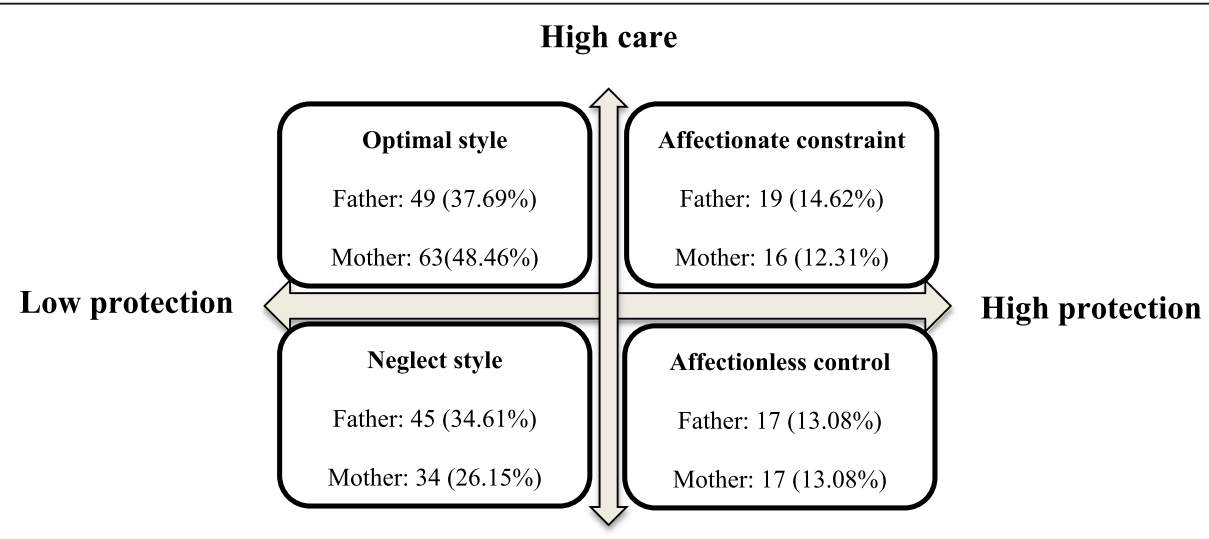

Low care

Fig. 1 Overall frequency of parental bonding styles in psychiatric patients 
Table 3 Frequency of parental bonding styles in psychiatric patients

\begin{tabular}{|c|c|c|c|c|c|c|}
\hline \multicolumn{2}{|c|}{ Parental bonding styles } & \multirow{2}{*}{$\begin{array}{l}\text { DepressionFrequency (\%) } \\
4(9.1)\end{array}$} & \multirow{2}{*}{$\begin{array}{l}\text { BipolarFrequency (\%) } \\
1(2.3)\end{array}$} & \multirow{2}{*}{$\begin{array}{l}\text { SchizophreniaFrequency (\%) } \\
11(25.6)\end{array}$} & \multirow{2}{*}{$\begin{array}{l}\boldsymbol{x}_{(\mathbf{6})}^{2} \\
17.66\end{array}$} & \multirow{2}{*}{$\begin{array}{r}\boldsymbol{P} \text {-value } \\
0.007\end{array}$} \\
\hline Mother & Affectionate constrains & & & & & \\
\hline & Affectionless control & $5(11.4)$ & $4(9.3)$ & $8(18.6)$ & & \\
\hline & Neglect style & $10(22.7)$ & $17(39.5)$ & $7(16.3)$ & & \\
\hline & Optimal style & $25(56.8)$ & $21(48.9)$ & $17(39.5)$ & & \\
\hline \multirow[t]{4}{*}{ Father } & Affectionate constrains & $5(11.4)$ & $5(11.6)$ & $9(20.9)$ & 2.67 & 0.848 \\
\hline & Affectionless control & $6(13.6)$ & $7(16.3)$ & $4(9.3)$ & & \\
\hline & Neglect style & $16(36.4)$ & $15(34.9)$ & $14(32.6)$ & & \\
\hline & Optimal style & $17(38.6)$ & $16(37.2)$ & $16(37.2)$ & & \\
\hline
\end{tabular}

Rejection of the children, refusal to interact with them and failure to express feelings are but examples of such behaviors [27]. As a warm and positive parent-child relationship can strengthen children's self-regulatory abilities [28] and create a sense of security in them [29], a cold and emotionally neglected relationship can preclude positive experiences in children.

The present study also showed a significant difference among the patients in terms of maternal bonding styles; in this regard, the most inefficient style was "affectionate constraint" (high protection, high care) in schizophrenic patients. Some researchers hold that inefficient parental bonding styles contribute to mental disorders by impacting children's cognitive systems and beliefs. They propose that cognitive beliefs and schemas can predict and determine behaviors and emotional responses based on the hypotheses of cognitive models. In some individuals, these behaviors and emotional responses lead to identity crisis, ineffective defense mechanisms, and maladaptive and pathological behaviors [30]. A study on a group of delinquent prisoners assessed the effects of different parental styles on their beliefs and cognitive schemas. According to their results, most of the prisoners' parents used affectionate constraint. In this style, parents exert excessive control and care over their children. The prisoners also reported that excessive control caused negative cognitive schemas, such as social isolation and dependence. In fact, this study considered a process that explained the effects of parental bonding styles on the children's mental health [31].

In terms of parental control, the results of the present study are in line with a study that examined parenting styles in people running high risks of psychosis and a study that investigated schizophrenic patients for parenting styles [32, 33]. Another study in Iran emphasized the relationship between the symptoms of psychiatric disorders and affectionless control parenting (high protection, low care) in parents. Their results also emphasized the relationship between maternal low care styles and psychological symptoms while introducing affectionless control style as a strong predictor of the severity and frequency of mental illness symptoms, especially depression [19]. These contradictory results imply the need for more studies in this field.

In the present study, neglectful style (low protection, low care) was the most common inefficient parenting style among the mothers of depressed patients. One study, conducted in Italy, examined a number of adolescents with "alexithymia"; they showed the relationship between "parental bonding styles" and alexithymia in adolescents. In particular, the maternal care style was associated with problems concerning the "explanation and expression of emotions" in adolescents. These problems, which are obvious features of alexithymia, were observed in the maternal neglectful style. The foregoing study also revealed that inefficient paternal styles, especially in the low care style, could be strong underlying causes of alexithymia. Furthermore, the studied adolescents were susceptible to mental disorders, such as depression, schizophrenia, and anxiety [34]. Alexithymia is known as a personality trait which prevents individuals from regulating their emotions and causes them to have problems with identifying, describing, and interpreting their own and others' emotions. Some studies have introduced alexithymia as an underlying factor for the development of mental disorders [35, 36]. In addition, some parental bonding styles, low care styles in particular, are positively correlated with alexithymia; therefore, can argue that inefficient parental styles, especially those based on low care, can be considered as underlying factors for the development of mental disorders.

According to our findings, parental bonding in schizophrenic patients has interesting characteristics. These patients perceived their parental bonding as paternal low care/ maternal high care and paternal low control/ maternal high control. In a longitudinal study on groups of patients with anxiety, depression, or both, depressed patients reported that their fathers did not provided adequate levels of "care" during the first 16 years of their lives [37]. In other words, the depressed patients suffered from the lack of a warm, loving, and close relationship with their fathers. A study on a large sample size in the 
United States also examined the association between parental styles and 13 common psychiatric illnesses; they observed a strong relationship between parental low care and psychiatric disorders [38].

\section{Strength and limitations}

To the best of our knowledge, the present study was the first in Iran to investigate three important psychiatric disorders in terms of their relationship with parental bonding. Similar to other studies, the present study had some limitations. Firstly, a major limitation of this study is the lack of healthy controls. Because there is no comparison with healthy controls, it is difficult to discuss the impact of the parental bonding on the diagnoses. However, comparing our data to the ones in literature on the general population [17-19], it should be noted that psychiatric patients are more often affected by ineffective parental bonding styles. Secondly, this study only examined the southern part of Iran with specific cultural and social characteristics which could influence the parental styles and the participants' perception of them. Furthermore, the samples were taken through convenience and non-random methods, which would probably affect the generalizability of the results.

\section{Conclusions}

The results of the study emphasized that parenting styles could be considered as predictors and predisposing factors for mental disorders. Moreover, all patients received low maternal care and bipolar patients experienced excessive control from both parents. These results shed more light on the important role of parents in developing the children's mental health by emphasizing childhood and adolescence. Our findings further confirmed that while there are several biological and psychosocial factors involved in the development of mental disorders, the role of parents, especially mothers, should be considered in mental health promotion strategies. Planners and executers of mental health programs should revise family education programs and provide necessary training for families on the importance of parents' appropriate and optimum care and control for their children.

\section{Abbreviations}

PBI: Parental Bonding Instrument; BD: Bipolar Disorder; MDD: Major Depressive Disorder

\section{Supplementary Information}

The online version contains supplementary material available at https://doi. org/10.1186/s12888-021-03177-3.

Additional file 1. Parental Bonding Instrument (PBI).

\section{Acknowledgements}

We would like to express our appreciation to the Clinical Research Development Center of Shohadaye Khalij Fars Hospital in Bushehr city.

\section{Authors' contributions}

Study design: MB, KM, SA; Data collection: AA, SA; Data analysis: KM, AA, MB; Manuscript writing: MB, AA, SA, KM. The author(s) read and approved the final manuscript.

\section{Funding}

This study was funded by Research Deputy of Bushehr University of Medical sciences. The funder had no role in the study implementation, data collection, data analyses or interpretation of study results.

Availability of data and materials

The datasets used and/or analyzed during the current study are available from the corresponding author on reasonable request.

\section{Declarations}

Ethics approval and consent to participate

The implementation of this study was approved by the Committee on Ethics at Bushehr University of Medical Sciences with the code number:

(IR.BPUMS.REC.1396.40). All procedures performed in study involving human participants were in accordance with the ethical standards of the

institutional and/or national research committee and with the 1964 Helsinki declaration and its later amendments or comparable ethical standards. All participants and parents/legal guardians gave their written informed consent after having been enlightened the details of the procedure. The participation in the study was voluntary and the participants could be excluded at any stage of the study.

Consent for publication

Not applicable.

\section{Competing interests}

The authors declare that they have no competing interests.

\section{Author details}

${ }^{1}$ Nursing and Midwifery School, Bushehr University of Medical Sciences, Bushehr, Iran. ${ }^{2}$ Nursing and Midwifery School, Shiraz University of Medical Sciences, Shiraz, Iran. ${ }^{3}$ Community Medicine, Medical School, Bushehr University of Medical Sciences, Bushehr, Iran.

Received: 4 December 2020 Accepted: 19 March 2021

Published online: 26 March 2021

\section{References}

1. Cooper C. Global, regional, and national incidence, prevalence, and years lived with disability for 354 diseases and injuries for 195 countries and territories, 1990-2017: a systematic analysis for the global burden of disease study 2017. Lancet. 2018:392(10159):1789-858.

2. Sadock BJ, Sadock VA, Ruiz P. Kaplan \& Sadock's synopsis of psychiatry : behavioral sciences/clinical psychiatry; 2015.

3. James SL, Abate D, Abate KH, Abay SM, Abbafati C, Abbasi N, et al. Global, regional, and national incidence, prevalence, and years lived with disability for 354 diseases and injuries for 195 countries and territories, 1990-2017: a systematic analysis for the global burden of disease study 2017. Lancet. 2018;392(10159):1789-858. https://doi.org/10.1016/S0140-6736(18)32279-7.

4. Mirghaed MT, Gorji HA, Panahi S. Prevalence of psychiatric disorders in Iran: a systematic review and meta-analysis. Int J Prev Med. 2020;11(21). https:// doi.org/10.4103/ijpvm.IJPVM_510_18.

5. Stilo SA, Murray RM. Non-genetic factors in schizophrenia. Curr Psychiatry Rep. 2019;21(10):100. https://doi.org/10.1007/s11920-019-1091-3.

6. Stapp EK, Mendelson T, Merikangas KR, Wilcox HC. Parental bipolar disorder, family environment, and offspring psychiatric disorders: a systematic review. J Affect Disord. 2020;268:69-81. https://doi.org/10.1016/j.jad.2020.03.005.

7. Williams E, Sands N, Elsom S, Prematunga RK. Mental health consumers' perceptions of quality of life and mental health care. Nurs Health Sci. 2015; 17(3):299-306. https://doi.org/10.1111/nhs.12189.

8. Mikulincer M, Shaver PR. An attachment perspective on psychopathology. World Psychiatry. 2012;11(1):11-5. https://doi.org/10.1016/j.wpsyc.2012.01. 003.

9. River LM, Borelli JL, Vazquez LC, Smiley PA. Learning helplessness in the family: maternal agency and the intergenerational transmission of 
depressive symptoms. J Fam Psychol. 2018;32(8):1109-19. https://doi.org/1 $0.1037 / f a m 0000479$

10. Shibata M, Ninomiya T, Anno K, Kawata H, Iwaki R, Sawamoto R, et al. Perceived inadequate care and excessive overprotection during childhood are associated with greater risk of sleep disturbance in adulthood: the Hisayama study. BMC Psychiatry. 2016;16(1):215. https://doi.org/10.1186/s12 888-016-0926-2.

11. Retherton I. The origins of attachment theory: John Bowlby and Mary Ainsworth. Dev Psychol. 1992;28(5):759-75. https://doi.org/10.1037/0012-164 9.28.5.759.

12. Marshall M, Shannon C, Meenagh C, Mc Corry N, Mulholland C. The association between childhood trauma, parental bonding and depressive symptoms and interpersonal functioning in depression and bipolar disorder. Ir J Psychol Med. 2018;35(1):23-32. https://doi.org/10.1017/ipm.2016.43.

13. Wilhelm K, Niven H, Parker G, Hadzi-Pavlovic D. The stability of the parental bonding instrument over a 20-year period. Psychol Med. 2005;35(3):387-93. https://doi.org/10.1017/s0033291704003538.

14. Eikenaes I, Egeland J, Hummelen B, Wilberg T. Avoidant personality disorder versus social phobia: the significance of childhood neglect. PLoS One. 2015; 10(3):e0122846. https://doi.org/10.1371/journal.pone.0122846.

15. Schorr MT, Tietbohl-Santos B, de Oliveira LM, Terra L, de Borba Telles LE, Hauck S. Association between different types of childhood trauma and parental bonding with antisocial traits in adulthood: a systematic review. Child Abuse Negl. 2020;107:104621. https://doi.org/10.1016/j.chiabu.2020.104621.

16. Gomes FG, Passos IC, Krolow AC, Reckziegel R, Vasconcelos-Moreno MP, Spanemberg $L$, et al. Differences in parental bonding between schizophrenia and bipolar disorder: evidence of prodromal symptoms? Schizophr Res. 2015;165(2-3):134-7. https://doi.org/10.1016/j.schres.2015.03. 032.

17. Lima AR, Mello MF, de Jesus Mari J. The role of early parental bonding in the development of psychiatric symptoms in adulthood. Curr Opin Psychiatry. 2010;23(4):383-7. https://doi.org/10.1097/yco.0b013e32833a51ce.

18. Hashimoto K, Sugawara N, Tanaka O, Nakamura K, Yasui-Furukori N. Parental bonding and attitudes toward suicide among medical college students in Japan. Neuropsychiatr Dis Treat. 2014;10:2015-20. https://doi.org/10.2147/ NDT.S70818.

19. Mashrouti P, Dolatshahi B, Mohamadkhani P, Pourshahbaz A, Mohammadi F. Parental traits in the relationship of type and severity of psychopathology in young adults. Pract Clin Psychol. 2017;5(4):297-304

20. Bahreini M, Akaberian S, Ghodsbin F, Yazdankhah Fard M, Mohammadi BM. The effects of parental bonding on depression and self esteem in adolescence. J Jahrom Univ Med Sci. 2012;10(1):6-10.

21. Honda J, Hohashi N. Discrepancies between couples' perceptions of family functioning in child-rearing Japanese families. Nurs Health Sci. 2015;17(1): 57-63. https://doi.org/10.1111/nhs.12148.

22. Parker $\mathrm{G}$, Tupling $\mathrm{H}$, Brown LB. A parental bonding instrument. Brit J Med Psychol 1979;52(1):1-0, 10, DOl: https://doi.org/10.1111/j.2044-8341.1979. tb02487. $x$

23. Behzadi B, Parker G. A Persian version of the parental bonding instrument: factor structure and psychometric properties. Psychiatry Res. 2015;225(3): 580-7. https://doi.org/10.1016/.jpsychres.2014.11.042.

24. Takahashi N, Suzuki A, Matsumoto Y, Shirata T, Otani K. Perceived parental affectionless control is associated with high neuroticism. Neuropsychiatr Dis Treat. 2017;18(13):1111-4. https://doi.org/10.2147/NDT.S132511.

25. Schimmenti A, Bifulco A. Linking lack of care in childhood to anxiety disorders in emerging adulthood: the role of attachment styles. Child Adolesc Mental Health. 2015;20(1):41-8. https://doi.org/10.1111/camh.12051.

26. Schimmenti A, Maganuco NR, La Marca L, Di Dio N, Gelsomino E, Gervasi AM. "Why Do I Feel So Bad?" Childhood Experiences of Emotional Neglect, Negative Affectivity, and Adult Psychiatric Symptoms. Mediterr I Soc Sci. 2015;6(6 S1):259-65. https://doi.org/10.5901/mjss.2015.v6n6s1p259.

27. Glaser D. Emotional abuse and neglect (psychological maltreatment): a conceptual framework. Child Abuse Negl. 2002;26(6-7):697-714. https://doi. org/10.1016/s0145-2134(02)00342-3.

28. Schore AN. Affect regulation and the repair of the self (Norton series on interpersonal neurobiology). New York: WW Norton \& Company; 2003.

29. Bowlby J. Clinical applications of attachment: a secure base, vol. 85. London: Routlege; 1988.

30. Thomas AM. An exploration of the relationship between childhood sexual abuse, caregiver support, and maladaptive cognitive schema among incarcerated women. Ohio: Doctoral dissertation, Ohio, University of AKRON 2008. Retrieved from https://etd.ohiolink.edu/.

31. Pellerone M, lacolino C, Mannino G, Formica I, Zabbara SM. The influence of parenting on maladaptive cognitive schema: a cross-sectional research on a group of adults. Psychol Res Behav Manag. 2017;10:47-58. https://doi.org/1 0.2147/PRBM.S117371

32. Peh $\mathrm{OH}$, Rapisarda A, Lee J. Quality of parental bonding is associated with symptom severity and functioning among individuals at ultra-high risk for psychosis. Schizophr Res. 2020;215:204-10. https://doi.org/10.1016/j.schres.2 019.10.029.

33. Roca Santos M, Vilaregut i Puigdesens A, Palma Sevillano C, Barón FJ, Campreciós Orriols M, Mercadal SL. Basic family relations, parental bonding, and dyadic adjustment in families with a member with psychosis. Community Ment Health J. 2020;56(7):1262-8. https://doi.org/10.1007/s1 0597-020-00581-z.

34. Mannarini S, Balottin L, Palmieri A, Carotenuto F. Emotion regulation and parental bonding in families of adolescents with internalizing and externalizing symptoms. Front Psychol. 2018;9:1493. https://doi.org/10.3389/ fpsyg.2018.01493.

35. Mannarini S, Balottin L, Toldo I, Gatta M. Alexithymia and psychosocial problems among Italian preadolescents. A latent class analysis approach. Scand J Psychol. 2016;57(5):473-81. https://doi.org/10.1111/sjop.12300.

36. Schimmenti A, Jonason PK, Passanisi A, La Marca L, Di Dio N, Gervasi AM. Exploring the dark side of personality: Emotional awareness, empathy, and the Dark Triad traits in an Italian Sample. Curr Psychol. 2019;38(1):100-9. https://doi.org/10.1007/s12144-017-9588-6.

37. Kullberg M-L, Maciejewski D, van Schie CC, Penninx BW, Elzinga BM. Parental bonding: psychometric properties and association with lifetime depression and anxiety disorders. Psychol Assess. 2020;32(8):780-95. https:// doi.org/10.1037/pas0000864.

38. ENNS MW, COX BJ, Clara I. Parental bonding and adult psychopathology: results from the US National Comorbidity Survey. Psychol Med. 2002;32(6): 997-1008. https://doi.org/10.1017/S0033291702005937.

\section{Publisher's Note}

Springer Nature remains neutral with regard to jurisdictional claims in published maps and institutional affiliations.
Ready to submit your research? Choose BMC and benefit from:

- fast, convenient online submission

- thorough peer review by experienced researchers in your field

- rapid publication on acceptance

- support for research data, including large and complex data types

- gold Open Access which fosters wider collaboration and increased citations

- maximum visibility for your research: over $100 \mathrm{M}$ website views per year

At $\mathrm{BMC}$, research is always in progress.

Learn more biomedcentral.com/submissions 